\title{
A reincidência do acontecimento no discurso jornalístico
}

\section{Beatriz Marocco}

Doutora; Universidade do Vale do Rio dos Sinos; São Leopoldo, RS, Brasil bmarocco@unisinos.br

\section{Resumo}

Este texto pretende esboçar um percurso teórico-metodológico para a compreensão da reincidência de um acontecimento arcano na reportagem "Cartão-postal do abandono", publicada em Zero Hora na edição de 10 e 11/12/2016. O projeto do governo brasileiro de repressão à ociosidade e às profissões desonestas, localizado pela autora em trabalho anterior, ocupa uma zona de sombra no conjunto de informações operadas pelo repórter de ZH. Em diferentes condições históricas de possibilidade, na virada do século XIX, a imprensa incluiu os indivíduos que desafiavam a ordem e o progresso nas cidades, para excluí-los da sociedade. $\mathrm{Na}$ atualidade, o repórter tece uma polifonia de vozes que produziram os mesmos sentidos de exclusão social, desta vez, incluindo outros personagens. Esta análise enunciativa de uma heterogeneidade de discursos lança luz sobre as relações de poder que estão em jogo na produção de relatos jornalísticos, ao longo da história.

\section{Palavras-chave}

Acontecimento. Discurso jornalístico. Exclusão social. Jornalismo.

\section{Introdução}

De posse de uma pequena coleção de informações históricas, o repórter de Zero Hora (ZH), Itamar Melo, trouxe à luz um sintoma do passado, "atravancado por problemas sociais", e a solução urbanística enviesada que o poder público replicou de metrópoles como Paris para embelezamento do Centro de Porto Alegre. Na década de 1920, explicou, quarteirões inteiros de construções irregulares foram demolidos para dar lugar àquela "imponente estrutura em estilo neoclássico" (MELO, 206, P.7). 0 local se tornou um cartão-postal, foi cenário de filmes, moldura para a foto de uma multidão de torcedores da Holanda, durante a 
última Copa do Mundo, mas a exemplo do que ocorrera no passado, "tornou-se símbolo de uma Porto Alegre inerte, suja, descuidada, repleta de miseráveis vivendo em suas ruas":

Vítima de abandono, desleixo e degradação, começou a concentrar moradores de rua a partir do verão passado e rapidamente transformou-se em acampamento de indigentes, drogados e doentes mentais. (MELO, 2016, p. 7).

Para além do que foi exposto pelo repórter, a reportagem apresenta sinais evidentes de parentesco com um conjunto de relatos produzidos por jornais porto-alegrenses entre o final do século XIX e as primeiras décadas do século passado. Ambos vinculam a ideia de "periculosidade ${ }^{1 "}$ e os seus referentes - a pobreza, a ociosidade, a enfermidade, a imoralidade - à construção das figuras dos indivíduos, que desafiavam e ainda desafiam a ordem social, e dos locais por onde circulavam e continuam circulando. Na virada do século XIX, a imprensa porto-alegrense registrou, regularmente, a presença de certos indivíduos que eram excessivamente numerosos e dificilmente controláveis, nas ruas do Centro da mesma cidade. No período entre o final do século XIX e meados do século passado, recém proclamada a abolição da escravatura, pequenas notas sinalizaram, com muita nitidez, as regiões da violência, a sujeira e a imoralidade que deveriam ser evitadas pelos cidadãos e suas famílias (MAROCCO, 2004).

Em sua produção regular, os relatos disseminaram a "periculosidade" em enunciados sobre o cotidiano de uma cidade decimonônica que vivia a ilusão do trabalho como o motor da vida e a fonte da riqueza e que, na realidade, tinha muitos problemas sanitários e de segurança que eram atribuídos aos indivíduos "perigosos". Desde a retórica governamental, era necessário enfrentar a tendência natural à vagabundagem do povo brasileiro, para responder às "esperanças patrióticas" de aumento da produção nacional, florescimento da agricultura e prosperidade da indústria e do comércio. Com educação e regeneração dos braços ociosos, que eram refratários ao trabalho, e com a repressão às profissões desonestas, o progresso não seria associado somente à imigração estrangeira:

Na verdade, não somente na imigração estrangeira que devem fundar-se as esperanças patrióticas de todos aqueles que desejam, pelo aumento da produção nacional, o florescimento da agricultura, da indústria, do comércio, a prosperidade do Brasil. A efetiva aplicação de braços ociosos, refratários ao trabalho, e a repressão de tendências à vadiagem, a mendicidade e a ocupações desonestas são outras tantas medidas que

\footnotetext{
1 A "periculosidade" (GARÓFALO, 1912; LOMBROSO, 1912) dava consistência a uma condição virtual, atribuída ao indivíduo não por seus atos, pelas infrações efetivas a uma lei que houvesse infringido, mas por um comportamento que poderia ter manifestado ou não, e que, em ambos os casos, deveria ser controlado (MAROCCO, 2004, p. 17).
} 
podem contribuir de modo eficaz ao desenvolvimento da sociedade. (BRASIL, 1888, p. 67).

Há um acontecimento fundador ${ }^{2}$ desta discursividade: o projeto do governo brasileiro de repressão à ociosidade e às profissões desonestas (Projectus 13 A-1888), apresentado à Câmara de Deputados do Brasil, em 10 de julho de 1888 , que tem permanecido na sombra dos discursos jornalísticos e que é fundamental para aproximar a prática contemporânea de outro limiar epistemológico do jornalismo. Um século depois, a reportagem publicada na edição do jornal Zero Hora, nos dias dez e onze de dezembro de 2016, fez emergir elementos destes relatos originais que deram base a "mapas da periculosidade" (MAROCCO, 2004, p. 95), em que os jornais daquela época criavam uma espécie de lado avesso dos guias práticos que orientavam as viagens cotidianas, na medida em que apresentavam os territórios hostis, bem marcados e localizáveis sobre a geografia da cidade.

De local turístico, as arcadas viraram teto para dezenas de desvalidos que ali montaram barracas ou levantaram tendas feitas de tábuas e de papelão. Uma ao lado da outra, elas se estendem ao longo de toda a construção, dos dois lados da Borges de Medeiros, oferecendo um cenário desolador para as pessoas que ainda se arriscam a circular por aí. (MELO, 2016, p. 7).

Para um mesmo acontecimento, em diferentes temporalidades e paradigmas do saber jornalístico, foram adotados procedimentos discursivos semelhantes. Nestas condições, o acontecimento pode ser problematizado no centro de uma série de negativas - não é substância nem acidente, não é qualidade nem processo, nem pertence à ordem dos corpos. Em sua incorporalidade material, no caso estudado, o acontecimento se materializa em uma natureza documental-discursiva própria do jornalismo. É no nível do real jornalístico que o acontecimento vai incorporar efeitos de poder. No jornalismo porto-alegrense, nestes termos, o relato articula as dimensões do presente, do passado e do que se possa esperar do futuro. Como esta articulação aparece, ou não, nos relatos analisados e como o vínculo temporal foi tecido no relato de ZH? As diferentes condições históricas de possibilidade, por outro lado, como já vimos, correspondem a diferentes limiares epistemológicos do jornalismo. Como o acontecimento é contado em diferentes atualidades pelos jornais? Como a informação é avaliada em sua vinculação com o passado pelo jornalista de ZH? Isto é, como

\footnotetext{
Apropriação direta do conceito de macroacontecimento fundador: "Os acontecimentos de todos os dias deverão ser enquadrados à imagem e semelhança deste macroacontecimento fundador [...]: todos os acontecimentos serão assim microrrelatos que reproduzem monadicamente a mesma cantilena. Em todos os cantos, o que encontramos é a redução dos valores da consciência empírica às verdades do senso comum." (MOREY, 1988, tradução nossa).
} 
o jornalista esclarece ou oculta o jogo de forças da sociedade imbricado na produção jornalística?

\section{Reconhecimento do agora}

A analítica para encaminhamento destas indagações sucede à atitude cognitiva, que exige do pesquisador um olhar fixo na superfície discursiva do agora e das ações em duas direções: na emergência de pistas da reincidência do acontecimento a serem contrastadas com o arquivo de enunciados organizado em pesquisa anterior (MAROCCO, 2004) e na organização de um novo arquivo de enunciados selecionados na superfície discursiva da reportagem de $\mathrm{ZH}$, em que é possível identificar marcas do macroacontecimento fundador. Benjamin (1940) reconheceu este transe cognitivo no caráter monadológico do tempo do agora, onde cada momento é continente para a história toda. Ao explorar as camadas históricas do subsolo discursivo, algumas figuras arcanas prenhes dos sentidos de exclusão social puderam ser reconhecidas no presente. Estas figuras permitem decifrar o que se insinua na ponta de um iceberg: a identificação da potência de um acontecimento na sombra de um acontecimento corrente, produzido em outras condições de possibilidade do jornalismo.

Neste sentido, em carta a G. Karplus, Benjamin escreveu:

Tomou corpo minha teoria do conhecimento que se cristaliza neste conceito que (previamente) manipulei de maneira muito esotérica, 'o reconhecimento do agora'. Descobri estes elementos da arte do seculo XIX que somente são reconhecíveis 'agora', que nunca o foram antes e nunca o serão outra vez (BENJAMIN, 1935, apud BUCK-MORSS, 1995, p. 70).

Além de reconhecer no presente, os mesmos efeitos de poder sobre o acontecimento, pode-se ampliar a análise ao trabalho do repórter e às práticas coetâneas de lidar com o tempo, com base em resultados obtidos por Garcin-Marrou (1996), em pesquisa sobre o "terrorismo", nas informações produzidas sobre a Irlanda do Norte. Garcin-Marrou voltou-se à compreensão do terrorismo, que se ancora na história e na atualidade, fixada em notícias produzidas por correspondentes internacionais na Irlanda de dois jornais - The Times e Le Monde -, sobre os atentados de outubro de 1993 e o cessar-fogo do Exército Republicano Irlandês (IRA), em setembro de 1994. Naquelas condições de possibilidade, era 
imprescindível a memória social, política e histórica do jornalista sobre terrorismo para a produção do acontecimento corrente, conforme uma dupla temporalidade, que conectasse latência à atualidade. Esta dupla temporalidade é que permite, segundo a pesquisadora, o sentido construído do acontecimento.

No processo de atribuição de sentido ou de valor ao acontecimento, o jornalista combina a leitura de símbolos ligados à informação - hora, lugar escolhido, tipo de atentado - e realiza a relação destes símbolos com a memória histórica - a similaridade com outros acontecimentos, a repetição ou a ruptura que a informação apresenta em relação a esta memória. (GARCIN-MARROU, 1996, p. 56, tradução nossa) ${ }^{3}$.

Na reportagem de Itamar Melo, ao contrário, o passado do jornalismo não pertence à memória de trabalho do jornalista. No entanto, seria possível preencher esta lacuna sobre a presença de indivíduos em situação de miséria nas ruas do Centro de Porto Alegre com pesquisa documental nos jornais da época, ou na literatura especializada em jornalismo. Para complexificar a analogia desenhada superficialmente, no exercício de acontecimentalização (FOUCAULT, 2006; MAROCCO; ZAMIN; BOFF, 2012), Melo poderia ter encontrado pistas da vinculação ao acontecimento fundador. Ao recorrer à história, de modo panorâmico, no entanto, o repórter não expandiu a pesquisa ao contexto sociopolítico, fazendo apenas eco de informações parciais e descontextualizadas. Manteve-se, assim, alinhado às operações de defesa da norma e dos valores que eram acionados no passado por uma retórica de combate a certos indivíduos, composta por um conjunto de táticas estratégicas tomadas de empréstimo de outros saberes.

A primeira era uma tática da medicina, que estendia aos discursos jornalísticos a missão de observar os corpos, diagnosticar e combater as enfermidades. Sua materialização nos discursos se dava através das metáforas orgânicas. A segunda era uma tática do saber criminológico, que se expressava nos discursos através da noção de "periculosidade". Sob influência da criminologia positivista e da medicina, os jornalistas consideravam pobres e delinquentes como enfermos e sugeriam a intervenção da polícia, ou dos médicos, ou a ação de ambos para promover um "saneamento" geral da cidade (MAROCCO, 2004, pp. 44-45). No século XXI, o lugar é o mesmo, são outros os indivíduos que agora têm voz, imagem e nome próprio. À diferença das figuras arcanas, que eram surpreendidas pelos jornalistas nos locais onde viviam e incluídas à revelia na representação, onde perdiam o corpo e não tinham

\footnotetext{
No original: "Dans le processus d'attribution du sens ou de valeur à l'événement, le journaliste combine donc la lecture des symboles liés à l'information - l'heure et le lieu choisis, ainsi que le type d'atentat - e t la mis en relation de ces symboles avec la mémoire historique - la similarité avec d'autres événements, la répétition ou la rupture que l'information que l'information présente par rapport à cette mémoire." (GARCIN-MARROU, 1996, p. 56).
} 
direito à voz, agora os indivíduos ocupam a função de fonte, são visibilizados e contam as suas histórias de abandono em entrevistas. Continuam, no entanto, na contramão do cotidiano da vizinhança afetada, que sempre teve um lugar proeminente na representação e na aquiescência do jornalista para denunciar os prejuízos que sofre com a presença do outro.

A reincidência na atualidade de um acontecimento fundador de discursividade evidencia que, ao contrário dos jornais brasileiros, os jornais estrangeiros tomam para si a formação dos jornalistas envolvidos na cobertura do terrorismo. Na Irlanda do Norte, os jornais incentivam os correspondentes novatos a acompanharem o trabalho dos veteranos antes de saírem a campo. Durante alguns meses, segundo entrevista feita por Garcin-Marrou com uma jornalista do Guardian, a apuração é compartilhada com o objetivo de enfatizar a importância da experiência prática como elemento que proporciona o aprendizado para construção mais precisa de uma intriga que, nos termos por ela emprestados de Paul Ricoeur (1983), permitem a identificação do acontecimento como uma entidade localizável.

Se falta ao jornalista o domínio do contexto sócio-político, ele pode conhecer o que se passou, mas não pode pôr-em-intriga, quer dizer, construir um acontecimento na história, dar sentido à informação. (GARCIN-MARROU, 1996, p. 50, tradução da autora) ${ }^{4}$.

\section{Jornalismo, tempo e poder}

Foucault pensou nas relações entre tempo e poder. No século XIX, segundo o pensador francês, foi constituída na sociedade uma rede institucional de sequestro para operar sobre o tempo dos indivíduos. Fizeram parte dessa rede um conjunto de instituições não estatais: pedagógicas, médicas, penais e industriais. 0 sentido da existência dessas instituições estava ligado ao tempo dos homens e à sua redução ao tempo de produção. 0 aparelho de produção deveria utilizar o tempo de vida, o tempo de existência dos homens. Segundo Foucault (1998, p. 130, tradução nossa):

É preciso que o tempo dos homens se ajuste ao aparelho de produção, que este possa utilizar o tempo de vida, o tempo de existência dos homens. Este é o sentido e a função de controle que se exerce. Duas são as coisas necessárias para a formação da sociedade industrial: por um lado é preciso que o tempo dos homens seja levado ao mercado e oferecido aos compradores que, por sua vez, o trocarão por um salário e por outro lado é

\footnotetext{
4 No original: "S'il manque au journaliste la maîtrise du contexte socio-politique, il peut certes avoir connaissance de ce qui s'est passé, mais il ne peut pas le mettre en intrigue, c'est a dire en faire un événement dans une histoire, bref en faire réellement une information." (GARCIN-MARROU, 1996, p. 50).
} 
preciso que se transforme em tempo de trabalho. A isso se deve que encontremos o problema das técnicas de exploração máxima de tempo em toda uma série de instituições.

Na sociedade feudal e nas sociedades primitivas o controle dos indivíduos se realizava, fundamentalmente, através de sua inserção local, pelo fato de que pertenciam a um determinado lugar. A inscrição geográfica era um meio de exercício do poder. Na sociedade moderna, que se formou a partir do século XIX, o sentido do controle dos indivíduos deslocou-se da terra para a cidade e, na cidade, para a fábrica e houve a necessidade de controle do tempo de trabalho e seus derivados, o tempo de descanso e o tempo de festa, à medida que apenas com o bom uso do tempo dentro e fora da fábrica o trabalhador era útil ao aparelho de produção. A rede de instituições de sequestro agia nestes sentidos - do tempo do trabalho, do tempo das festas e do ócio - para regular a totalidade da existência.

Nesta direção, o jornalismo brasileiro no final do século XIX deu visibilidade a mecanismos de sequestro dos corpos dos indivíduos que contrariavam o tempo da produção e eram igualmente alvo dos projetos de normalização do governo. Há marcas da existência de uma estratégia conjunta de valorização do trabalho e negativização das camadas perigosas da população formadas por indivíduos que se dedicavam à "vagabundagem" nos mais diferentes relatos: literários, governamentais e jornalísticas.

0 modo de objetivação jornalística, assim constituído, como vimos em pesquisa anterior (MAROCCO, 2004), fez o discurso funcionar como uma forma e uma prática de mediação simbólica que, simultaneamente, revela e oculta as operações de poder e abriga práticas disciplinares específicas para apresentar os indivíduos improdutivos e produzir efeitos de verdade sobre a sua "periculosidade". Através da crônica policial, os jornais apresentaram figuras em suas relações promíscuas e perigosas de modo a dar vazão à "periculosidade" e suspender a individualidade, ao tornar o corpo desses indivíduos, vetor de técnicas que combinam a hierarquia de quem observa a um julgamento moralista e normalizador. Os indivíduos ganharam uma existência verbal própria e mobilidade irrestrita no seio de uma grande família de cinco figuras básicas (MAROCCO, 2004):

a) os vagabundos e mendigos - muitos entre eles apenas resistiam ao trabalho na fábrica; eram operários que tinham se rebelado contra qualquer regularidade de horário ou de hábitos, escravos recém libertos, camponeses sem-terra para explorar, ou ex-soldados empobrecidos e desempregados após o final das guerras. Sob o ponto de vista dos jornais, todos eram malfeitores que contaminavam a cidade. Porto Alegre tinha sido contaminada por um conjunto 
de vagabundos malfeitores que era necessário corrigir severamente, "acabar com eles" (MAROCCO, 2004, p. 37);

b) as prostitutas - geralmente os jornalistas se referiam a elas como as crioulas, que chamavam a atenção pela sua pele escura e desafiavam a ordem nas ruas. Em sua figura jornalística, a prostituta era virtualmente perigosa. Tinha uma vida imoral que rompia com as normas e valores morais da vida coletiva. Era o germe de todos os vícios;

c) os jogadores - viviam do negócio do jogo e contaminavam o entorno; eram os vagabundos que se dedicavam ao jogo do osso nas ruas ou os pobres-diabos que poupavam para jogar e serviam de alvo fácil para a repressão policial. Eram, junto com os falsos mendigos e os ociosos, o grande referente da vagabundagem e da anormalidade. A síntese do mal que se opunha ao trabalho na fábrica e à família;

d) os jovens - na classificação jornalística, os jovens não eram nunca inocentes, jogavam e perturbavam a ordem nas ruas, frequentavam as tavernas ou viviam sob a proteção dos jogadores. As meninas eram normalmente vítimas, de pais abusadores e das mães que as prostituíam;

e) e os ladrões e criminosos - ao contrário dos tipos anteriores, que foram incluídos nos jornais no final do século, os ladrões e criminosos nasceram e o seu serlinguagem foi ganhando novas formas e volume, pouco a pouco, durante a história do jornalismo. No final do século, eram apresentados como "tipos esquisitos" que mantinham a cidade em constante sobressalto (MAROCCO, 2004, p. 43).

\section{Exercício de análise}

Com a trajetória acadêmica atualmente voltada a outro objeto de pesquisa, fui movida pelas pistas, que apontavam para a pertinência de uma análise enunciativa, no rastro da reincidência do acontecimento fundador que afeta a prática jornalística nas duas épocas. Um arquivo de enunciados deu lugar então a um estranho diálogo entre dois limiares de epistemologização do saber jornalístico - o primeiro em que o jornalismo é reconhecido como prática discursiva atravessada pela literatura, na passagem do século, e o segundo em que o jornalismo atual, organizado em um campo profissional pela objetividade, a verdade 
factual e a presença de fontes, que dão credibilidade ao campo jornalístico, é compreendido em sua singularidade por um conjunto organizado de teorias.

Na sequência do espanto que experimentei diante das estratégias semelhantes para objetivação de certos indivíduos, postulo, mais concretamente, a volta da "fábula moderna" nos textos jornalísticos do agora (MOREY, 1988; 2004). Ao objetivar o acontecimento em torno do qual se estruturou o cotidiano do trabalho e da normalidade, no período histórico que abrange o final da escravidão, início da industrialização e embelezamento das metrópoles mundiais, vinculados ao princípio republicano de "ordem e progresso", os jornais porto-alegrenses enquadraram a imaterialidade dos acontecimentos em fatos ligados à ordem social, que incluía certos indivíduos no discurso para reforçar sua "periculosidade". A mesma forma de exclusão reapareceu na reportagem de Zero Hora.

Os dois enunciados, que se constituem no principal recurso gráfico para a leitura da reportagem de Zero Hora, articulam o viaduto Otávio Rocha, construído em 1932, às qualificações de: "símbolo do descaso" e "cartão-postal do abandono". Na chamada de capa, o viaduto é apresentado como a obra que provocou uma "revolução em Porto Alegre" e que agora provoca "vergonha", ao abrigar em suas arcadas "uma população igualmente desassistida e que também simboliza nossa degradação como cidade" (MELO, 2016, p. 1 e 7). No interior do caderno, o enunciado "Cartão-postal do abandono" conduz a uma descrição histórica da Rua General Paranhos. Na versão do repórter, a estreita e sinistra General Paranhos era "quase um beco", que subia da Andrade Neves até a Duque de Caxias e depois "mergulhava” em direção à Coronel Genuíno (MELO, 2016, p. 7).

Recheada de cortiços e bodegas, refúgio de desocupados, era famosa por concentrar prostituição e crimes. Corcoveava o ponto mais elevado do Centro, um pico que bondes e automóveis não tinham força para transpor. Para deslocar pessoas e mercadorias da região do Mercado Público até o outro lado do morro, a zona da Ponte dos Açorianos, era necessário dar toda a volta pela beira do Guaíba, um problema que remontava aos primórdios da povoação, ainda no século XVIII. A General Paranhos era o símbolo de uma Porto Alegre atrasada, antiquada e atravancada por problemas sociais. (MELO, 2016, p. 7).

Nos jornais do passado ${ }^{5}$, são os enunciados que, sem aparentemente hierarquizar o noticiário, constroem um frágil enquadramento espacial para pequenas notas distribuídas nas páginas. Na virada do século, os "riferrafes" diários entre os soldados do 25ํㅡㄹathão de Infantaria e o proprietário do Restaurante Mocidade, a disputa entre um cabo e o "crioulo" Francisco Gonçalves pelo amor da meretriz Odorica, ou a perseguição de dois cidadãos por

${ }^{5}$ Foram pesquisados os seguintes jornais de Porto Alegre: Gazetinha, Gazeta da Tarde, O Independente e O Século. 
um par de soldados bêbados que acabavam de sair de uma taverna, compunham a imagem de promiscuidade atribuída à Rua General Paranhos (PESAVENTO, 1998, p. 125; MAROCCO, 2004, p. 102).

Na década seguinte, 0 Independente afirmava que as tavernas do Beco do Poço, como era popularmente conhecida a rua, eram preferidas para a libertinagem (PESAVENTO, 1998, p. 125; MAROCCO, 2004, p. 102). No Beco do Poço localizavam-se os prostíbulos da "crioula" Fausta e da "crioula" Domingas. As calhas eram outro problema do beco. Segundo se pode ler na Gazetinha, as calhas estavam quase sempre cheias de lixo (MAROCCO, 2004, p. 103). No início do século XX começaram as operações urbanísticas para mudar o desenho dos becos e o espaço que os cortiços ocupavam na cidade. Simultaneamente, começava o trabalho jornalístico de difamação destas regiões que se concentravam no centro da cidade.

Foi neste beco que se manifestou o primeiro caso de peste bubônica de Porto Alegre, seguindo-se muitos outros não só de peste, como também varíola, febre tifóide e outras moléstias contagiosas. Os registros de polícia estão repletos de delitos no beco praticados, desde o assassinato até o estupro, sendo raro o dia em que não se dêem desordens mais ou menos graves. Isto quanto ao ponto de vista da tranquilidade, quanto ao da higiene, está afinado pelo mesmo diapasão. Os moradores são ou vagabundos incorrigíveis ou prostitutas da mais baixa esfera, infelizes que às vezes nem têm o que comer e que, para poderem pagar o aluguel das casas, aglomeram-se as vezes seis ou oito em casas que com dificuldades conteriam três moradores. Nessas casas, a imundície era das mais flagrantes, sendo os apartamentos ao mesmo tempo sala, dormitório, sala de jantar, cozinha e latrina. (O INDEPENDENTE, 1906).

Na década de 1920, quarteirões inteiros foram demolidos. A General Paranhos deu lugar a uma larga avenida, a Borges de Medeiros, que permitiu o acesso direto da Zona Sul à área central e, "coroando o empreendimento", um vão aberto no morro foi preenchido pelo Viaduto Otávio Rocha, "imponente" estrutura em estilo neoclássico, dotado de escadarias, parapeitos, escadas e lojas.

O viaduto era o símbolo de uma Porto Alegre moderna, próspera e vibrante, orgulhosa de si mesma. Durante décadas, foi um cartão-postal incontornável, cenário de filmes, de ensaios fotográficos e de comerciais de grandes marcas nacionais e internacionais. Em 2014, forneceu a imagem mais icônica da realização da Copa do Mundo em Porto Alegre: a de uma multidão de torcedores da Holanda emoldurados por sua estrutura, com roupas e bandeiras cor de laranja, a caminho do Estádio Beira-Rio. A foto, uma celebração de alegria e plasticidade, correu o mundo. Foi como um último suspiro. (MELO, 2016, p. 7). 
Dois anos após ter sido usada de cenário para os torcedores da Holanda, as arcadas "viraram teto para dezenas de desvalidos" (MELO, 2016, p. 7). Ao longo da extensão do viaduto, barracas ou tendas construídas de tábuas e papelão abrigam "indigentes, drogados e doentes mentais", oferecendo "um cenário desolador para as pessoas que ainda se arriscam a circular por ali" (MELO, 2016, p. 7). O repórter de Zero Hora desdobrou a aparência do lugar em uma descrição detalhada e atravessada por sentidos que parecem estranhos em relação à condição de ilegalidade e à precariedade da existência dos indivíduos. Na conta do repórter, há trinta espaços ocupados, alguns por somente um morador, outros compartilhados por casais ou amigos. Nos mais "simples" há um colchonete encostado à parede; a maioria, no entanto, "é bem mais incrementada", porque não houve resistência das autoridades à ampliação dos domínios pelos denominados ironicamente de "inquilinos do viaduto".

\footnotetext{
Em geral, cada lar tem um pequeno aposento de tábuas, com um teto feito de lona preta ou outro material. No interior, todos estão dotados de colchões. À porta de um, alinha-se com capricho um par de fantufas, as pontas voltadas para fora. Em várias destas moradias, um pátio foi demarcado na calçada, e nesses quintais é possível contemplar um tapete com arabescos, uma poltrona, estantes feitas com caixotes e até uma mesa improvisada a partir de uma caixa de papelão, coberta por uma toalha corde-rosa e ornamentada por um vaso de flor e um porta-retratos sem foto alguma. (MELO, 2016, p. 7).
}

Ao contrário da maioria dos jornalistas da passagem do século, que eram narradores oniscientes e onipotentes do cotidiano dos indivíduos, o repórter de $\mathrm{ZH}$ deu voz aos indivíduos que, desde meados do século XX, ganharam o lugar de "fontes". Houve mudança nas práticas, entretanto, os mesmos valores morais ligados ao trabalho, à propriedade e à família acabaram predominando no exercício narrativo de apresentação dos indivíduos. Marli Pereira Pires, de 52 anos, "estendida em um dos colchões", contou para o repórter que foi frentista, faxineira e pintora de paredes. Caiu de um andaime, não pode mais trabalhar e recebeu até dois anos atrás um auxílio mensal de cerca de mil reais do INSS. Depois de perder tudo o que tinha foi para um albergue, enjoou e passou por vários lugares na rua. Ela gosta de "ficar" no viaduto porque ali tem um teto contra as intempéries e banheiro público. Pelo relato é possível saber que Pereira Pires tem filhas e netos, que ela se preocupa com os netos e que sabe notícias deles somente por telefone, porque a filha tem vergonha de visitála. 
Aqui é bom porque tem esses padrinhos que vêm durante a noite e trazem comida. E além disso eu me dou com muitos andarilhos aqui. Todo mundo me chama de tia e me respeita. (MELO, 2016, p. 8).

Melo e os jornalistas da virada do século deram ouvidos aos moradores da região. Os "vizinhos" eram os auxiliares diretos mais frequentes dos jornalistas, embora não fossem identificados. Como os jornalistas reconheciam, os vizinhos costumavam pedir-lhes, por exemplo, que reclamassem, em seu nome, ações de repressão policial contra, por exemplo, "batuques infernais dos negros", ou contra "bailes de lupanar" que reuniam as meretrizes nos becos mais escuros da cidade (MAROCCO, 2004, p. 67). 0 repórter que ouviu Pereira Pires, fez entrevistas com a presidente da Associação Comunitária do Centro Histórico, que mora em um prédio na vizinhança, Ana Maria Lenz, com o líder da Associação Representativa e Comercial do Viaduto Otávio Rocha (Arcovv), Adacir Flores, proprietário de uma loja de livros usados, situada na parte inferior do viaduto, e com Renato Pereira Jr., proprietário do Armazém Porto Alegre, um pub instalado há quatro anos nas escadarias do viaduto. Os três deram apoio ao diagnóstico da vizinhança "exasperada" e dos "prejuízos ao comércio". Conforme Melo, Lenz mostrou-se preocupada com a insegurança, a sujeira, o mau cheiro, o consumo de drogas e as gritarias na madrugada.

Fazem xixi, fazem sexo e se drogam no viaduto. À noite, o barulho é terrível, porque eles dormem durante o dia. Tem assaltos. Quem é que sofre com todos esses problemas? Os moradores dos edifícios próximos. Estamos cansados. (MELO, 2016, p. 8).

Adacir Flores, conforme Melo, citou o prejuízo que a ocupação trouxe para os concessionários de espaços comerciais. Alguns estabelecimentos fecharam e os que continuam têm menos movimento de fregueses e queda no faturamento, a ponto de estarem em dificuldade para cobrir os custos.

Isso aqui virou uma cracolândia. Consomem e traficam direto. Tem também delinquentes que foram corridos das vilas. Mais para baixo fica uma mulher que é doente mental, transa com todo mundo e lava os genitais na frente dos carros, como se estivesse lavando as mãos. (MELO, 2016, p. 08).

\section{5 À modo de conclusão e um recomeço}

$\mathrm{Na}$ reportagem "Cartão-postal do abandono", Melo sintetizou a experiência dos jornalistas de final de século ao ocupar uma posição de defesa do "símbolo de uma Porto 
Alegre moderna, próspera e vibrante", dedicando-se à escuta do cotidiano dos moradores de rua na entrevista com Pereira e nos dois depoimentos que transcreveu em duas colunas denominadas "vozes do viaduto". Para além deles, situado no limiar da "objetividade jornalística", o repórter apresentou o outro lado da questão, em que transcreveu as reclamações contra a presença dos moradores de rua.

As operações dos jornalistas no passado e na atualidade me levaram a cogitar, inicialmente, na mobilização da "dupla temporalidade", proposta por Garcin-Marrou (1996). No entanto, como o repórter de Zero Hora se restringiu a reproduzir a fábula moderna, a dupla temporalidade foi transferida para a função do analista, inscrita no âmbito da acontecimentalização. As relações enunciativas entre os enunciados recortados da imprensa porto-alegrense da virada do século e da reportagem de ZH levaram à compreensão do signo longitudinal da exclusão e das figuras que foram construídas. As cinco figuras bem delineadas pelos jornais decimonônicos - dos vagabundos e mendigos, prostitutas, jogadores, jovens e ladrões - foram substituídas pela presença na representação dos "semteto", qualificação genérica, para designar delinquentes, sujos, drogados e baderneiros, usada pelo repórter e por vizinhos incomodados com o impacto no seu cotidiano e com os prejuízos no comércio. As autoridades foram responsabilizadas por não corresponderem às demandas por melhorias da vizinhança. Os sujeitos envolvidos com assistência social, em suas diferentes atribuições, ou reconheceram que o problema "ainda não está no nosso horizonte", ou que "Uma das coisas que favorecem muito a permanência ali é o lado caritativo, ser um local onde há muita entrega de doações." ${ }^{7}$.

Ao final, poder-se-ia projetar uma dimensão de futuro - novas reincidências do mesmo acontecimento no noticiário -, com base no que se observava no passado na leitura dos jornais: a recorrência da intervenção policial para repressão de quem não se ajustava à norma. No sábado, dia em que Zero Hora circulou, os moradores de rua foram retirados para limpeza do viaduto onde, no domingo, ocorreria a festa de comemoração de seus 84 anos. Na madrugada de domingo para segunda, os sem-teto voltaram ao viaduto. Embora o responsável pela operação de limpeza tenha negado a relação direta com a reportagem de Zero Hora, é difícil não realizar novas relações com os enunciados arcanos em que os jornalistas agiam e se reconheciam como auxiliares da polícia e das autoridades sanitárias, usando o espaço do jornal para visibilizar onde os indivíduos viviam e por onde circulavam.

\footnotetext{
${ }^{6}$ Declaração do vice-prefeito eleito de Porto Alegre, Gustavo Paim (MELO, 2016, p. 11).

7 Declaração de Lirene Finkler, psicóloga da proteção social especial da Fundação de Assistência Social e Cidadania (Fasc), responsável por políticas para a população de rua (MELO, 2016, p. 12).
} 
E por falar em indigentes, lembre a sábia polícia municipal o grande número de vagabundos que andam esmolando por estas ruas [...]. Diariamente vem pelas ruas da capital um robusto italiano, conduzindo pela mão um rapaz cego, que, dedilhando uma sebosa sanfona anda de porta em porta esmolando. (MAROCCO, 2004, p. 37).

Dois anos depois de encerrado este artigo, jornalistas e policiais participaram de novas ações sincrônicas de divulgação e repressão do que se identificou no parágrafo anterior como dimensão de futuro do mesmo acontecimento fundador. A repórter Gabrielle de Paula do canal G1 descreveu as "calçadas vazias", no texto "Viaduto Otávio Rocha em Porto Alegre fica sem barracas e moradores de rua após ações policiais" (PAULA, 2018, doc. não paginado). Os policiais ouvidos por ela afirmaram que não haviam encontrado mais moradores de rua e sim usuários de drogas e traficantes que foram abandonando o lugar em consequência do policiamento. "Estava se criando uma cracolândia no Centro [...]. Com as abordagens diárias, os traficantes não ficam.", explicou à repórter o tenente-coronel Rodrigo Mohr, do 9o Batalhão de Polícia Militar (PAULA, 2018, doc. não paginado). Outras fontes consultadas no texto: Deyvid Soares, representante do Movimento Nacional de População de Rua (MNPR), e o presidente da Associação Representativa e Cultural dos Comerciantes do Viaduto Otávio Rocha (ARCCOV), Adacir Flores. "Fomos pegos de surpresa. Mas hoje, para quem trabalha aqui, ficou mais tranquilo", disse Flores (PAULA, 2018, doc. não paginado). Dois dias depois, food trucks, bike foods e trailers ocuparam o viaduto Otávio Rocha. A repórter do Jornal do Comércio (JC), Suzy Scarton, recolheu depoimentos de vários consumidores que reconheceram a "ocupação do bem", que a cidade precisava. Sobre o destino dos moradores de rua, tanto Scarton quanto de Paula creditaram à Prefeitura a falta de informações. Ao contrário de Melo, as duas repórteres não procuraram entrevistar os sem-teto, que já insinuavam um movimento de volta, no outro lado da avenida, observados pelo presidente da Associação de Gastronomia Itinerante do Rio Grande do Sul, Neno Guterres. Para ele, o sucesso do negócio está ligado à ocupação do local durante todos os dias da semana. Com o espaço ocupado, prefeitura e comerciantes acreditam que os moradores de rua não voltarão para lá. De acordo com o secretário de Desenvolvimento Econômico, Luis Antônio Steglich, a intenção é ocupar o viaduto também nos dias de semana. "Vamos trabalhar para consolidar o local, para que seja mais um atrativo a empreendedores e visitantes.", afirmou (SCARTON, 2018, doc. não paginado). Com isso, pode-se concluir que um problema estrutural da sociedade brasileira recebe invariavelmente o mesmo tratamento do poder público desde o século XIX. Desta vez, 
entretanto, a expulsão dos moradores do viaduto da Borges foi pensada para atender, diretamente, as demandas da sociedade de consumo.

\section{Referências}

BENJAMIN, Walter. Sobre o Conceito de História. In: BENJAMIN, Walter. Magia e técnica, arte e política. São Paulo: Brasiliense, 1987. tese XIV, p. 230.

BRASIL. Congresso Nacional. Câmara dos Deputados. Annaes do Parlamento Brazileiro. Terceira Sessão da Vigésima Legislatura. De 4 de julho a 2 de agosto de 1888. Rio de Janeiro: Imprensa Nacional, 1888. v. 3, p. 67-75. Projectus 33 A-1888.

BUCK-MORSS, Susan. Dialéctica de la mirada: Walter Benjamin y el proyecto de los Pasajes. Madrid: La Balsa de la Medusa, 1995.FOUCAULT, Michel. La verdad y las formas jurídicas. Barcelona: Gedisa, 1998.

FOUCAULT, Michel. Qu'est-ce que la critique? Critique et Aufklärung. Bulletin de la Société française de philosophie. [s.l.], v. 84, n. 2, p. 35-63, 2008.

GARÁFOLO, Rafaelle. La criminología. Madrid: Daniel Jorro editor, 1912.GARCIN-MARROU, Isabelle. L'événement dans l'information sur L'Irlande du Nord. Réseau, [s.l.], v. 14, n. 76, p. 47-60, 1996.

LOMBROSO, Cesare. El delito. Madrid: Librería General de Victoriano Suárez, 1912.

MAROCCO, Beatriz, ZAMIN, Angela; BOFF, Felipe. Os grandes acontecimentos e o reconhecimento do presente. Verso e Reverso, São Leopoldo, v. 26, n. 62, p. 92-102, 2012.

MAROCCO, Beatriz. Prostitutas, jogadores, pobres e vagabundos no discurso jornalístico. São Leopoldo: Editora Unisinos, 2004.

MEDINA, Cremilda. Notícia: um produto à venda. São Paulo: Editora Alfa-Omega, 1978.

MELO, Itamar. Símbolo do descaso. Zero Hora, Porto Alegre, p. 6-12, 10 e 11 dez. 2016.

MOREY, Miguel. El orden de los acontecimientos: sobre el saber narrativo. Barcelona: Ediciones Provincia, 1988.

MOREY, Miguel. Reconhecimentos do agora. In: MAROCCO, Beatriz. Prostitutas, jogadores, pobres e vagabundos no discurso jornalístico. São Leopoldo: Editora Unisinos, 2004, p. 711.

O INDEPENDENTE, Porto Alegre, 18 fev. 1906.

PAULA, Gabriele de. Viaduto Otávio Rocha em Porto Alegre fica sem moradores de rua após ações policiais. G1, [Porto Alegre], 29 ago 2018. Rio Grande do Sul.

PESAVENTO, Sandra. Os pobres da cidade. Porto Alegre, Editora da Universidade, 1998. 
RICOER, Paul. Temps et récit, tome 1 \& 3. Paris: Seuil, 1983.

SCARTON, Suzy. Prefeitura planeja ocupação permanente do Viaduto da Borges. Jornal do Comércio, Porto Alegre, 6 ago. 2018. Geral.

\title{
The recurrence event in journalistic discourse
}

\begin{abstract}
This text presents a theoretical-methodological basis to understand the recurrence of an arcane event in the article "Postcard of the abandonment", published by Zero Hora in the edition of december $10^{\text {th }}$ and december $11^{\text {th }}, 2016$. The Brazilian's government project to repress idleness and dishonest professions (Projectus $13 \mathrm{~A}-1888$ ), located by the author in previous research, occupies a shadow zone in the set of information operated by the $\mathrm{ZH}$ reporter. Under different historical conditions of possibility, at the turn of the nineteenth century, the press included on its pages the individuals who challenged order and progress in cities to exclude them from society. Nowadays, the reporter weaves a polyphony of voices that produced the same sense of social exclusion over other characters. Enunciative analysis of heterogeneous discourses sheds light on the power relations in the production of journalistic information.
\end{abstract}

\section{Keywords}

Event. Journalistic discourse.Social Exclusion. Journalism.

Recebido em 17/04/2019

Aceito em 15/08/2019 